\title{
2014 Doob Prize
}

CÉDRIC VILLANI was awarded the Joseph L. Doob Prize at the Annual Meeting of the AMS in Baltimore, Maryland, in January 2014.

\section{Citation}

Optimal Transport, Old and New. Grundlehren der Mathematischen Wissenschaften [Fundamen-

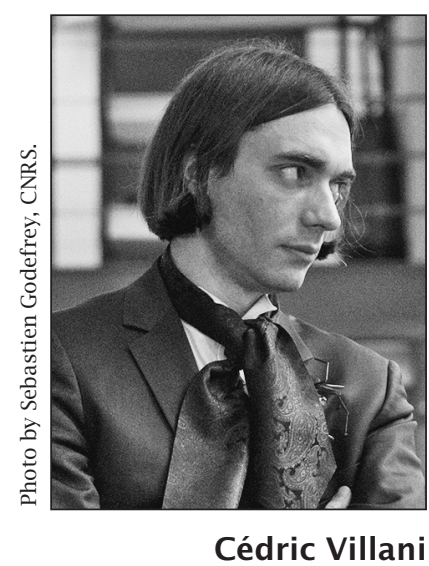
tal Principles of Mathematical Sciences], 338. Springer-Verlag, Berlin, 2009.

In 1975 the mathematicians Leonid V. Kantorovich and Tjalling C. Koopmans received the Nobel Prize in Economics "for their contributions to the theory of optimum allocation of resources." Subsequent research on optimal transport has revealed remarkable connections with such varied areas of mathematics as dynamical systems, geometry, and partial differential equationsand also with applications ranging from fluid mechanics to meteorology to cosmology.

This book represents a profound rethinking of the subject of optimal transport by one of its leading contributors. The overarching themes are existence, uniqueness, regularity, and stability of optimal transport; and the investigation of Riemannian geometry via optimal transport. Many results appear here in book form for the first time, often in sharper versions than have previously been published. The scope of the volume is breathtaking: the panorama of topics from dynamics, probability, and geometry includes Moser's technique for coupling smooth positive probability measures, Caffarelli's log-concave perturbation theorem, Kantorovich duality, the Wasserstein distance between probability measures, Mather's shortening lemma, the Ma-Trudinger-Wang tensor, a priori estimates for solutions of the Monge-Ampère equation, the Bochner-Weitzenböck-Lichnerowicz formula, the Brunn-Minkowski inequality in nonnegatively curved Riemannian manifolds, the Bakry-Émery theorem, Lichnerowicz's spectral gap inequality, Talagrand inequalities, the measured Gromov-Hausdorff topology, and Ricci curvature bounds on metric spaces.

A pedagogical masterpiece, the book effectively communicates deep ideas while remaining relatively self contained. Engaging historical and bibliographical commentaries further enliven the DOI: http://dx.doi.org/10.1090/noti1112 exposition. J. L. Doob was known for the loving care that he lavished on his books, especially Classical Potential Theory and Its Probabilistic Counterpart (like Optimal Transport, published in the Springer Grundlehren series). Cédric Villani's readers will recognize a worthy heir to Doob's legacy of outstanding mathematical research exposition.

\section{Biographical Sketch}

Born in 1973 in France, Cédric Villani studied mathematics at the École Normale Supérieure in Paris, from 1992 to 1996, and spent four more years as assistant professor there. In 1998 he defended his Ph.D. on the mathematical theory of the Boltzmann equation. Besides his advisor PierreLouis Lions (Paris, France), he was much influenced by Yann Brenier (Nice, France), Eric Carlen (Rutgers, USA) and Michel Ledoux (Toulouse, France).

He was professor at the École Normale Supérieure de Lyon from 2000 to 2010 and is now at the Université de Lyon. He has occupied visiting professor positions in Atlanta, Berkeley, and Princeton. Since 2009 he has been the director of the Institut Henri Poincaré in Paris; this eightyyear-old national institute, dedicated to welcoming visiting researchers, is at the very heart of French mathematics.

His work has won him many national and international prizes, in particular the Fields Medal, presented at the 2010 International Congress of Mathematicians in Hyderabad by the President of India. His book Théoréme vivant (Broché, 2012) retraces the genesis of the development of the theorem of Landau damping, the subject for which he was awarded the Fields Medal. Since then he has served as a spokesperson for the French mathematical community in media and political circles.

His main research interests are in kinetic theory (Boltzmann and Vlasov equations and their variants) and optimal transport and its applications, a field in which he wrote the two reference books, Topics in Optimal Transportation (2003) and Optimal Transport, Old and New (2008).

\section{Response from Cédric Villani}

Books are immaterial children, born out of an intense intellectual experience. Often they acquire a living on their own and impose themselves to you. I never experienced this feeling better than when composing Optimal Transport, Old and New, which was part of my life for three years. I had

\footnotetext{
${ }^{1}$ Théorème vivant was reviewed by Jacques Hurtubise in the February 2014 issue of the Notices.
} 
initially planned this book to be a 100-page-long summer school proceeding, and in the end it was a 1000-page-long reference book. This quick growth and change of ambition was the book's decision, not mine. The state of obsession which I arrived at while working on it is almost unparalleled in my personal history. After it was finished, I would often open it at a random page and read it, like a father proudly contemplating his newborn. Fortunately it was not only to his father's taste, since the book has been doing well and has become a classical reference in the field of optimal transport. That it is rewarded with the Doob Prize is a great honor for me; I especially like the reference to Doob, who had the same care for details and presentation as I try to have-always thinking hard about the best way to present and convey messages to the readers' minds, without sacrificing the rigor in the least. But this prize is also for me a mere joy, and the occasion to commemorate what I consider as one of the happy events in my life.

\section{About the Prize}

The Doob Prize was established by the AMS in 2003 and endowed in 2005 by Paul and Virginia Halmos in honor of Joseph L. Doob (1910-2004). Paul Halmos (1916-2006) was Doob's first Ph.D. student. Doob received his Ph.D. from Harvard in 1932 and three years later joined the faculty at the University of Illinois, where he remained until his retirement in 1978. He worked in probability theory and measure theory, served as AMS president in 1963-1964, and received the AMS Steele Prize in 1984 "for his fundamental work in establishing probability as a branch of mathematics and for his continuing profound influence on its development." The Doob Prize recognizes a single, relatively recent, outstanding research book that makes a seminal contribution to the research literature, reflects the highest standards of research exposition, and promises to have a deep and longterm impact in its area. The book must have been published within the six calendar years preceding the year in which it is nominated. Books may be nominated by members of the Society, by members of the selection committee, by members of AMS editorial committees, or by publishers. The prize of US $\$ 5,000$ is given every three years.

The Doob Prize is awarded by the AMS Council acting on the recommendation of a selection committee. For the 2014 prize, the members of the selection committee were Harold P. Boas, William Fulton, Philip J. Holmes, Neal I. Koblitz, and John H. McCleary.

The previous recipients of the Doob Prize are William P. Thurston (2005), Enrico Bombieri and Walter Gubler (2008), and Peter Kronheimer and Tomasz Mrowka (2011).

\section{Morgan Prize}

ERIC LARSON was awarded the 2014 AMS-MAASIAM Frank and Brennie Morgan Prize for Outstanding Research in Mathematics by an Undergraduate Student at the 120th Annual Meeting of the AMS in Baltimore, Maryland, in January 2014.

\section{Citation}

Eric Larson is awarded the 2014 AMS-MAA-SIAM Frank and Brennie Morgan Prize for Outstanding Research by an Undergraduate Student for his truly exceptional record of research. He has so far authored or coauthored eight papers, two as sole author, two with Dmitry Vaintrob, three with Larry Rolen, and one with David Jordan. His papers have appeared in a wide spectrum of research journals, including Advances in Geometry, Bulletin of the London Mathematical Society, Forum Mathematicum, the Journal of Noncommutative Geometry, and Proceedings of the American Mathematical Society.

DOI: http://dx.doi.org/10.1090/noti1114
Eric began his research work while still in high school, working in the REU program at Penn State University under Sergei Tabachnikov and then at the Research Science Institute at the Massachusetts Institute of Technology under Pavel Etinghof. In 2010, after his first year at Harvard, Eric participated in Ken Ono's REU program at the University of Wisconsin. This led to his collaboration with Dmitry Vaintrob. Eric continued in Ono's REU, now at Emory University, in 2011 and again in 2013. His work in this program resulted in five papers. In 2012 Eric received a summer research fellowship to work with Joe Harris at Harvard, producing another paper.

In addition to his stellar research work, Eric also won the Intel Science Talent Search first place prize, took second place in the Siemens competition that same year, and won a gold medal at the 